called The Face of Science. Overtaken by events, it never saw the light of day. In November 1942, Allied forces landed in North Africa, prompting the Germans to invade previously unoccupied southern France, rendering the Vichy government impotent. The photos were consigned to the museum library.

In 1990, the museum invited Doisneau back to complete his project. This postscript was a good idea: the contrast between the two sets of photos speaks volumes. Doisneau was in his late seventies and famous. The museum, too, had changed, and Doisneau delighted in discovering its three new subterranean floors of storage. The later images are as closely observed as the earlier ones. But now - as in a picture of a stuffed gorilla in a lift, emerging from or descending into the museum's bowels - the irony is less loaded, and the delight floats free.

Laura Spinney is a writer and science journalist based in Paris.

e-mail:lfspinney@gmail.com

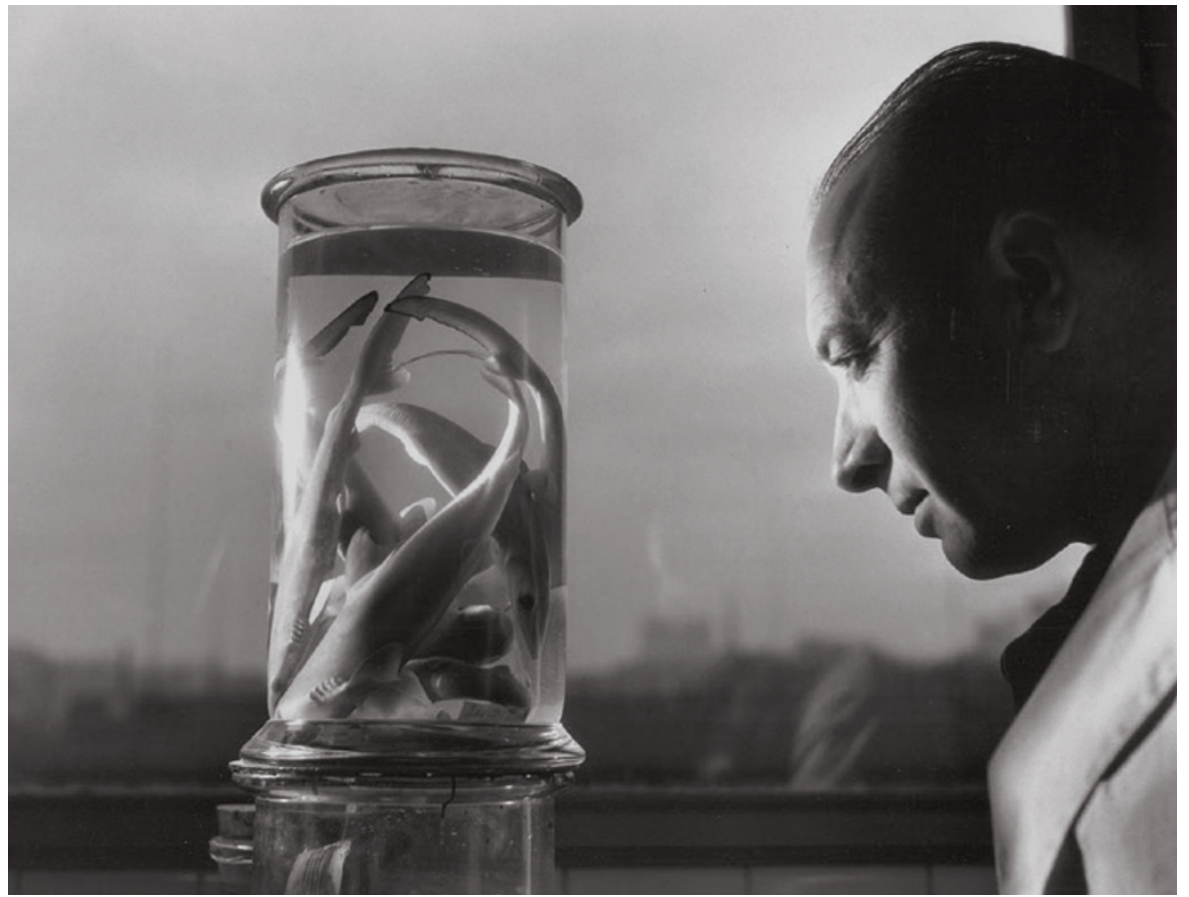

Paul Budker of the Laboratory of Fish and Colonial Animals with a jar of baby sharks in 1943.

\title{
Tales of the unexpected
}

\section{Stuart Firestein relishes Helga Nowotny's study of uncertainty in science and society.}

$\mathrm{F}$ or scientists, uncertainty is a norm. Experiments begin with uncertainty (why else do them?), and even when they are 'successful', the results contain only a range of certainty and a range of confidence about that certainty. Yet in the world outside the laboratory, uncertainty is perceived as negative - not a data point, but a failing, effectively no better than not knowing.

Social scientist Helga Nowotny, former president of the European Research Council, has written The Cunning of Uncertainty, a tour of the phenomenon and its value to the individual researcher, to the infrastructure of research and to society. Coping with uncertainty, Nowotny declares, must become a collective achievement. Otherwise, the scientific community risks becoming an elite, with all the suspicion and mistrust that that engenders.

As Nowotny shows in numerous examples from the social sciences, historical literature and current media, society's misunderstanding of uncertainty has already led to confusion, distortion and politicization of science (in the debates on tobacco and on climate change, for instance). Billions of dollars of public and private money are poured into research, largely on the false assumption that science provides cold, hard, immutable facts. This attitude is reinforced by an educational system that treats science as an immense 'fact tract' to be memorized (and then largely forgotten), producing a populace that believes science is about answers, rather than questions.

Nowotny deserves high praise for bringing a discussion of the uncertainty around uncertainty into the public arena. She does so with remarkable aplomb given the subject's slipperiness. She challenges scientists to take a leading role in setting straight the distorted views of certainty in science, and then spreading the word to educational and political policymakers.

I was puzzled at first by Nowotny's use of "cunning", a term denoting a worrisome craftiness - cleverness mixed with predatory wiliness. However, Nowotny has nailed

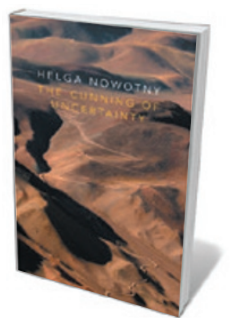

The Cunning of Uncertainty HELGA NOWOTNY Polity: 2015. it: uncertainty has a duality. It is a space that allows creativity, but it is fraught with insecurity. Nowotny herself struggles to disentangle uncertainty from the unexpected, the unpredictable, the dangerous. She sometimes fails, but the exercise is instructive. We take too much for granted, she shows, in defining uncertainty; there are many subtleties and layers to it. From antiquity, people used prognosticators and magicians to look into the future; futurologists are still consulted. Yet people insist on 'spoiler alerts' before sports results are announced, or in film or book reviews; and few want to guess, much less know, the exact moment and circumstances of their too-certain deaths. Definitely cunning.

Nowotny examines this tension through historical examples of how policy is set in areas of uncertainty. These are: reproductive technologies such as in vitro fertilization; stem-cell science; and personalized medicine. With the exception of the last example, these seem like old stories. A discussion of more current and contentious policies, such as genetically modified organisms or nuclear power, might have been more instructive. However, her analyses of big-data programmes (the trumpeted then debunked 
Google Flu Trends is an excellent example) and nonlinear complex systems (such as finance, energy or pandemics) as gushers of uncertainty and contemporary spaces of innovation make for deep and fruitful reading.

Although she gives us chapter headings like those of a self-help book ('Craving for certainty', 'The odds for tomorrow'), Nowotny refuses to be

"Treating science as a 'fact tract' to be memorized produces a populace that believes science is about answers, rather than questions." prescriptive - at least in this volume. Rather, she presents us with many ideas and numerous angles to chew over. My personal favourite is her tracking of public attitudes to risk, from viewing it as both negative and positive to seeing it as an almost completely negative factor that must be reduced. Her ideas about positive risk and why it must be increased offer a refreshing perspective in this compliance-oriented world.

This is, above all, a book of ideas, not a policy manual, even though Nowotny would obviously like to see changes in funding, economic and management policies. She is well-equipped to lead us in this battle; throughout an illustrious academic career, she has served in numerous policymaking positions, for example in the European Science Foundation. And that is perhaps the one thing that I miss in this book: a more personal tour of uncertainty with a traveller who has come up against it in policy, funding, education and research. It is a shame that Nowotny does not occasionally put down the careful scholarly pen and take up the memoirist's.

As a scientist, I am at home with uncertainty. I like that the gathering of knowledge inevitably reveals new and unexpected bits of a vast unknown akin to the dark matter of epistemology. The real cunning of uncertainty lies in how it increases through every attempt to reduce it.

As for certainty, wherever you find it, you can be sure that a demagogue or dictator is nearby. French author and Nobel laureate André Gide advised that we should believe those who seek the truth - and doubt those who claim to have found it. This is one prescription that Nowotny courageously follows.

Stuart Firestein is the former chair of the Department of Biological Sciences at Columbia University in New York City. His latest book is Failure: Why Science Is So Successful.

e-mail:sjf24@columbia.edu

\section{Books in brief}

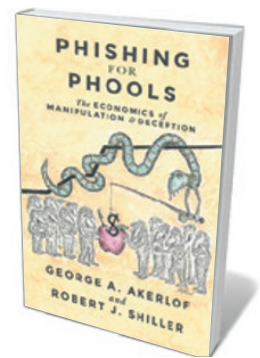

Phishing for Phools: The Economics of Manipulation and Deception

George A. Akerlof and Robert J. Shiller PRINCETON UnIV. PRESS (2015)

In this acerbic dissection of free-market economics, Nobelprizewinning economists George Akerlof and Robert Shiller trash the "invisible hand" theory, which claims that self-interest promotes social benefits. They reveal market economies as rife with trickery "phishing" luring "phools" to make poor choices. The two pool their economic wisdom to analyse arenas from food buying and politics to the financial crisis that has plagued us since 2008. A needed call for sceptical economics and financial mindfulness.

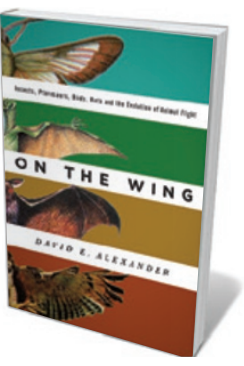

On the Wing: Insects, Pterosaurs, Birds, Bats and the Evolution of Animal Flight

David E. Alexander OXFORD UnIV. PRESS (2015)

How do dragonflies, vultures or fruit bats fly? Biomechanics specialist David Alexander reveals all in this study of flight and the evolution of wings in pterodactyls, bats, birds and insects. Aloft with Alexander, we learn how pilots have observed phalanxes of swans flying at 8,000 metres, and how the gargantuan pterosaur Quetzalcoatlus northropi probably got off the ground. Alexander analyses aerial predation, sex, combat, sleep and even egg-laying; picks at the puzzle of bats' evolutionary relationships; and much more.

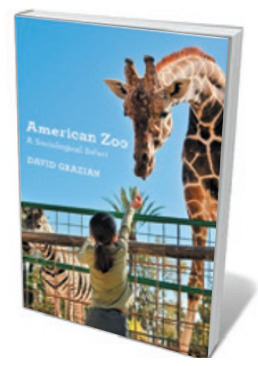

\section{American Zoo: A Sociological Safari}

David Grazian PRINCETON UNIV. PRESS (2015)

Cultural sociologist David Grazian once studied urban nightlife. Turning to another brand of contained wildness, he immersed himself in zoos. As a volunteer, he clipped a ferret's toenails, bathed tortoises and logged "more working hours of animal husbandry and faecal cleanup" than most professors can boast. His trek through 26 US zoos has yielded a powerful portrait of these conservation-hotspots-cumliving-labs - which end up telling us more about ourselves than about the animals. Peppered with delicious details, such as one zoo's use of the film Austin Powers for animal "enrichment".

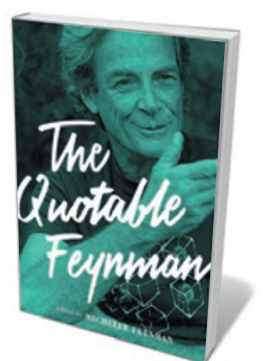

\section{The Quotable Feynman}

Edited by Michelle Feynman PRINCETON UNIV. PrESS (2015)

The Nobel-prizewinning, bongo-playing, exuberant and brilliant physicist Richard Feynman died in 1988. His contributions to science (including the theory of quantum electrodynamics) and science popularization ensure a lasting fame (R. Phillips Nature 504, 30-31; 2013). His daughter Michelle has mined interviews, articles, books and lectures for this collection of quotes on everything from poetry to politics. Feynman's depth and zing leap from the page, as in: "What I am trying to do is bring birth to clarity, which is really a half-assedly thought-out pictorial semi vision thing."

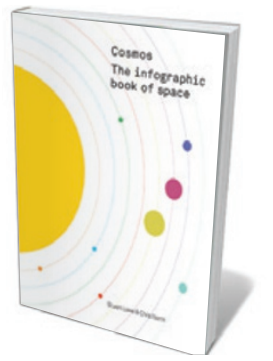

Cosmos: The Infographic Book of Space

Stuart Lowe and Chris North AURUM (2015)

Infographics remain on a roll, offering visual insight into abstruse regions of human knowledge. Astronomers Stuart Lowe and Chris North really lift off in this graphic exploration of all things space. Their depictions of year-by-year spaceflights and space junk shock through sheer numbers, while their takes on interplanetary missions, moons in the Solar System and particularly the polarization of the Milky Way — like a cosmic finger-painting in palest mauve - deliver the facts with aesthetic brio. Barbara Kiser 